\title{
Correspondence
}

\section{Ankylosing spondylitis, HLA-B27, and klebsiella: cross reactivity and antibody studies}

SIR, The association of klebsiella with HLA-B27 involves two separate theoretical models which have been the subject of some debate, recently discussed by Singh et al, ${ }^{1}$ and deserve further comment.

The first model deals with cross reactivity or molecular mimicry (cross tolerance hypothesis) between HLA-B27 and antigens found in some Gram negative bacteria (klebsiella, shigella, and yersinia), which we first proposed some 10 years ago. ${ }^{2}$ In this model there is no difference between HLA-B27 positive lymphocytes obtained from either patients with ankylosing spondylitis (AS) or healthy controls.

The second model deals with bacterial cross reactivity which is present only in HLA-B27 positive lymphocytes obtained from patients with AS but not in those lymphocytes obtained from healthy controls. ${ }^{3}$

We would like to bring to your notice that three other independent centres have published reports of cross reactivity between Gram negative bacteria (klebsiella, shigella, and yersinia) and HLA-B27. Van Bohemen and coworkers from Amsterdam, using anti-B27 monoclonal antibodies provided by Grumet from Stanford in California, showed that anti-B27(M1) reacted with a protein component in two klebsiella strains (K21 and K43) and Yersinia enterocolitica type $9 .{ }^{4}$ Kono and coworkers from Los Angeles produced an anti-Yersinia enterocolitica monoclonal antibody which reacted with 12/12 B27 lymphoblastoid cell lines, but with only 4/31 B27 negative ones. ${ }^{5}$ Three of the four reactive B27 negative cell lines carried B7, an HLA antigen that cross reacts with HLA-B27. Trull and Panayi from Guy's Hospital (London) produced a mouse anti-klebsiella serum which reacted in microlymphocytotoxicity assays with 5/7 B27 positive lymphocytes and with $0 / 13$ B27 negative lymphocytes. ${ }^{6}$ It was interesting to note that $2 / 5$ of the reactive lymphocytes came from healthy B27 positive individuals.

Table 1 Levels of antibodies in patients with active AS, inactive disease, and in controls*

\begin{tabular}{lllll}
\hline & Active $A S$ & $\begin{array}{l}\text { Probably } \\
\text { active } A S\end{array}$ & Inactive AS & Controls \\
\hline Mean \pm SE & $79 \cdot 1 \pm 5 \cdot 4$ & $58 \cdot 1 \pm 4 \cdot 1$ & $41 \cdot 1 \pm 3 \cdot 5$ & $38 \cdot 7 \pm 4 \cdot 8$ \\
Number & 6 & 9 & 8 & 20 \\
\hline
\end{tabular}

* Results are expressed as percentages of inhibition.
Furthermore, antibodies to klebsiella have been shown, by us, to be present in patients with active ankylosing spondylitis, using three different techniques: enzyme linked immunosorbent assay, ${ }^{78}$ bacterial absorption, ${ }^{9}$ and indirect Coombs' bacterial agglutination, ${ }^{10}$ while no such increases were found against Escherichia coli, candida, salmonella, yersinia, pseudomonas, streptococcus, and proteus micro-organisms. In a further study, using ${ }^{125} \mathrm{I}$ labelled klebsiella antigen in a radioimmunoassay, higher levels of antibodies were found in sera obtained from patients with active AS (paper in preparation) than in sera from patients with inactive disease $(p<0.001)$ and controls $(p<0 \cdot 001)$. The results are summarised in Table 1.

The demonstration of specific antibodies to klebsiella by four different techniques is independent of the results of the cross reactivity studies. Thus the association of klebsiella with AS is based not only on cross reactivity studies carried out by us and the above mentioned centres, but also on serological studies involving several techniques, as well as microbiological investigations.

In view of the fact that four independent centres have published positive evidence about cross reactivity between Gram negative bacteria and HLA-B27 it would appear to us that the phenomenon of cross reactivity or molecular mimicry (cross tolerance hypothesis) has clearly been confirmed, at least in some centres.

Immunology Unit,

A EBRINGER

Department of Biochemistry,

King's College,

London W8

Department of Rheumatology,

The Middlesex Hospital,

London W1

\section{References}

1 Singh B, Milton J D, Woodrow J C. Ankylosing spondylitis, HLA-B27, and klebsiella: a study of lymphocyte reactivity of anti-klebsiella sera. Ann Rheum Dis 1986; 45: 190-7.

2 Ebringer A, Cowling P, Ngwa-Suh N, James D C O, Ebringer $\mathrm{R} W$. Cross reactivity between Klebsiella aerogenes species and B27 lymphocyte antigens as an aetiological factor in ankylosing spondylitis. In: Dausset J, Svejgaard A, eds. $H L A$ and disease. Paris: INSERM, 1976; 58: 27.

3 Seager K, Bashir H V, Geczy A F, Edmondes J, De Vere Tyndall A. Evidence for a specific B27 associated cell surface marker on lymphocytes of patients with ankylosing spondylitis. Nature 1979; 277: 68-70.

4 Van Bohemen Ch G, Grumet F C, Zanen H C. Identification of HLA-B27 M1 and M2 cross reactive antigens in klebsiella, shigella, and yersinia. Immunology 1984; 52: 607-9.

5 Kono D H, Ogasawara M, Effros R B, Park M S, Waldord R L, Yu D T Y. Ye-1, a monoclonal antibody that cross-reacts with HLA-B27 lymphoblastoid cell lines and an arthritis causing bacteria. Clin Exp Immunol 1985; 61: 503-8.

6 Trull A K, Panayi G S. Further observations on klebsiella molecular cross-reactivity in HLA-B27 positive persons. $J$ Rheumatol 1985; 12: 1024. 
7 Trull A, Ebringer R, Panayi G S, Colthorpe D, James D C O, Ebringer A. IgA antibodies to Klebsiella pneumoniae in ankylosing spondylitis. Scand J Rheumatol 1983; 12: 249-53.

8 Trull A, Ebringer A, Panayi G, Ebringer R. James D C O. HLA-B27 and the immune response to enterobacterial antigens in ankylosing spondylitis. Clin Exp Immunol 1984; 55: 74-80.
9 Ebringer A, Baines M, Childerstone M, Ghuloom M, Ptaszynska T. Etiopathogenesis of ankylosing spondylitis and the cross-tolerance hypothesis. In: Ziff $\mathrm{M}$, Cohen S B, eds. The spondyloarthropathies. Adv Inflamm Res 1985; 9: 101-28.

10 Ebringer A, Ptaszynska T, Corbett M, et al. Antibodies to proteus in rheumatoid arthritis. Lancet 1985;ii:305-7.

\section{Book review}

Clinics in Rheumatic Diseases: Osteoarthritis. Edited by Leon Sokoloff. Pp. 444. £15·00. Saunders: Eastbourne. 1985.

This is another good volume in a consistently good 'review' journal. Sokoloff as editor has chosen to cover the topic in its widest sense, and his own description of rare endemic forms of osteoarthritis (Kashin-Beck and Mseleni disease) is comprehensive and encourages the search for environmental influences in the multifactorial pathogenesis of the common disorders of local or generalised osteoarthritis.

In a chapter on pathogenesis Dr Cooke treads neatly through the issues of mechanical and inflammatory contributions to the final pathology of joint destruction. Distinguishing metabolic features and the inverse relation between osteoarthritis and osteoporosis are well set out by Dequeker; and Dieppe and Watt make the case for crystals being an 'opportunistic' event in osteoarthritis, yet in certain disease subsets it is felt they do not remain as innocent bystanders.

In contrast, there is good advice on clinical aspects of management from Dr Rudd and the Swansons, although I wonder if the 'grind test' for $x$ ray negative early osteoarthritis of the interphalangeal joints may not be considered an iatrogenic contribution to the pathology by
Dr Cooke. Other issues such as the osteochondrodysplasias and endocrine arthropathies are clearly presented, and Hadler's critique of several decades of epidemiological studies ends on a hopeful note for bigger analyses with clearer outcomes in the future.

Although one might question its inclusion in a volume on osteoarthritis, I personally enjoyed several dips into DISH (diffuse idiopathic skeletal hyperostosis) with $\mathrm{Dr}$ Utsinger. This is a common disease, which fortunately has a low morbidity. There are suggestions of a primary metabolic cause which may be elucidated by the study of newer relevant animal models.

As with previous volumes this is a comprehensive review of osteoarthritis which will be of use to most jobbing rheumatologists, and may stimulate newcomers to investi- $\frac{\bar{c}}{\omega}$ gate certain aspects of this common disease. Only regular subscribers might recognise the thinly disguised reissue of a chapter on drug therapy of osteoarthritis which appeared $\stackrel{\circ}{\circ}$ in the August 1984 volume. The authors have, however, been consistent over 12 months.

Senior Registrar,

Northwick Park Hospital, and

Hon Clinical Lecturer

Middlesex Hospital Medical School

\section{Clinical vignette}

\section{The 'L4 syndrome' as a cause of obscure knee symptoms}

The deep pain referral territory (sclerotome) of the fourth lumbar segment includes the knee and anterior region. Irritative lesions of the fourth lumbar nerve root are often poorly localised to their site of origin, especially in the absence of back symptoms. The patients may complain of obscure and ill defined discomfort in the knees or anterior legs, or of the knees 'giving way' or 'feeling weak' on walking. Elderly patients may even fall. Although the distribution of symptoms often suggests a local cause, examination at the site of symptoms for local anatomical abnormalities of the knees or other lower limb structures is often negative. There may, however, be referred tenderness as well as pain. Any or all of the following physical signs may be present:

(a) local tenderness in the region of the fourth lumbar spinal segment on firm pressure with the patient lying prone;

(b) restriction of movement or muscle spasm, or both, at the same spinal level, with increased discomfort in the symptomatic leg on lateral flexion to one or other side.
In addition, on the affected side there may be:

(c) a positive femoral nerve stretch sign;

(d) weakness of hip flexors;

(e) depression of patellar reflex;

(f) disturbance of light touch or pain sensation in the anterior knee and tibial area;

(g) tenderness at the insertions of tendons in the popliteal fossa.

The symptoms and signs may be relieved by reducing $\frac{T}{O}$ traction on the femoral nerve roots, as with flexing the hips. and knees to about 30 degrees by resting the knees over $\mathbb{N}$ pillows in the supine position. Conversely, symptoms may be provoked by increased traction on the femoral roots, as 0 when lying prone or supine with hips and knees fully $\underset{\omega}{\omega}$ extended. Symptoms may temporarily increase during the recovery phase after this latter posture is relaxed. As 6 prolonged sitting or standing erect may provoke pain, perching stools and the new kneeling chairs offer an ergonomic approach to management.

Rheumatology Unit,

Southampton General Hospital,

Shirley,

Southampton SO9 4XY 